\section{Remaking the Universe}

Laurie M. Brown

The Second Creation: Makers of the Revolution in Twentieth-Century Physics. By Robert P. Crease and Charles C. Mann. Macmillan, New York: 1986. Pp. 480. \$25.

THE serious popularization of science is a difficult art, one that requires a broad grasp of the scientific enterprise considered and a discriminating sense of its history. Included in the latter are intellectual development, social setting, principal actors and their backgrounds and personalities. Its authors should combine a strong pedagogical urge with a talent for writing readable prose, and they should be able to simplify, without oversimplifying. In most respects, The Second Creation is a satisfying popularization of what may be the most glamorous and philosophically nourishing part of this century's physics (though by no means the part of greatest economic, social or political importance). Unfortunately, this otherwise admirable work is marred by some incorrect and misleading scientific statements, all the more distressing as they could have been caught by any competent physics student. The deeper parts of the subject fare better than the rudiments, perhaps explaining why the errors were not pointed out by the eminent scientists who, according to the authors, "read and commented, sometimes copiously, upon early drafts of chapters".

Robert Crease, who is a graduate student in philosophy at Columbia University, and Charles Mann, who is a writer on science and technology, set out to describe the growth of elementary particle physics, emphasizing recent developments and providing minimal background in the ideas of quantum mechanics. Original citations are in evidence, but the book is based mainly on a limited number of secondary sources; it relies heavily on recent conferences organized by physicists to study the history of their subject. The authors attended some of these conferences and also visited the leading workplaces, taking advantage of these occasions to interview 125 physicists and to obtain a few unpublished documents.

Before enlarging on the positive side of this book, let me indicate the kind of error that I referred to in the first paragraph. In the discussion of Planck's quantum hypothesis (p. 24), it is stated that the oscillators are restricted to discrete frequencies; they are not, it is their energies that are quantized. Again, the first example of a matrix that is shown (on p. 49 ) is not a matrix at all: the "numbers" 1 and 2 appearing in the two by two array actually represent Child 1 and Child 2, that is the names of children. (No rule is given for the multiplication of such names!) A new way of obtaining relativistic electrons is proposed (p. 81): "What happens when a flashlight beam hits a wall? The electrons in the wall absorb and emit photons, in the process moving at the enormous velocities where relativity is

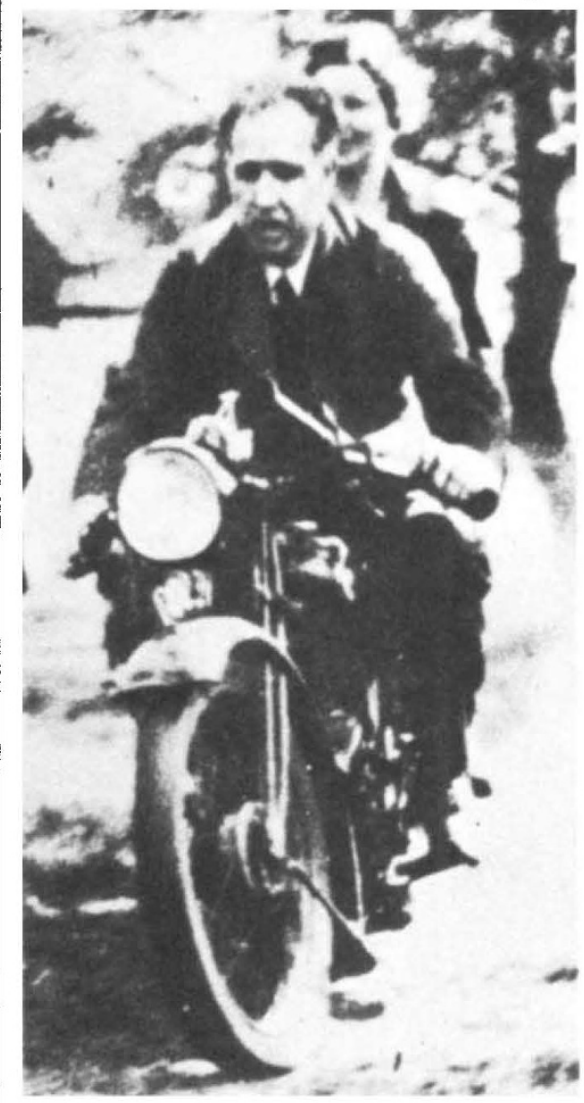

On his bike - Niels Bohr, with his wife, photographed by George Gamow. The picture is taken from Gamow's Thirty Years That Shook Physics: The Story of Quantum Theory, which was first published in 1966 and has now been reissued by Dover, New York/Constable, London.

important." In discussing the famous tau-theta puzzle of the $1950 \mathrm{~s}$, which led to the discovery of the breakdown of parity conservation in weak interactions ( $p$. 204), the authors explain: "A stationary pion has a parity of -1 . Ignoring a few additional factors [my emphasis], the twopion decay has a total parity of $-1 \times-1-=+1$. The three pion decay has a parity of $-1 \times-1 \times-1=-1$. In this way the tau and theta were distinguished."

In view of such blatant nonsense, how can I call this a satisfying popularization?
(And what could possibly justify the enthusiastic blurbs of distinguished physicists on the book jacket?) For one thing, the density of howlers of the type I have quoted is not high, less than one per ten pages. For another, the book is fun to read: its colourful journalistic style, the enthusiasm of the scientists whose interviews make up the major, and by far the most valuable part of the text, and the intrinsic drama of the creation of the socalled Standard Model (the present, perhaps only temporary, candidate for "the end of physics") make the book difficult to put down. As a writer on the history of physics, I can be only envious of the way the authors evoke a particular scientist's personality in a brief paragraph or two.

In comparing The Second Creation with a serious and scholarly history that was greatly praised in these pages $(\mathbf{3 2 1}, 123)$ not long ago, Abraham Pais's Inward Bound (only Part I is called a "history" by Pais, Part II being a "memoir"), one must assume that they are addressed to rather different audiences. Pais writes down many equations and emphasizes technical points that are essentially inaccessible to anyone without an advanced degree in physics. Crease and Mann err in the opposite direction: some of their arguments, as I have tried to show, are too simplistic to be meaningful. Perhaps there is no solution to the dilemma of pedagogy versus readability. The knowledgeable reader will simply ignore the "explanations" of things that he knows better, and the novice will have to glean what he can of the intellectual structure, while getting a sense of the excitement of the chase, the conflict of personality and the rest of the human drama.

Regarding the quality of the history gained from the interviews, it is probably comparable to, though not as high as that in, say, the famous Archives for the History of Quantum Physics (mostly the work of Thomas Kuhn and collaborators). In the latter case, the interviewers prepared themselves carefully in advance, and often challenged the physicist being interviewed or confronted him with his own earlier accounts. One does not get the impression that the present authors were anything but sympathetic and accommodating to the views presented by their scientific informants, who seemed only too glad to engage in philosophically rambling (and at times, perhaps, self-serving) accounts of their achievements, and of their brilliant, but unpublished, anticipatory hunches. Almost all the legends and myths of particle physics are repeated, often in several voices, which shows that they are either really true or truly myth, I suppose.

Laurie M. Brown is Professor of Physics and Astronomy, Northwestern University, Evanston, Illinois 60201, USA. 